\title{
Modeling and Simulation of 115.2 kWp Grid-Connected Solar PV System using PVSYST
}

\author{
Ashok Aryal*, Nawraj Bhattarai \\ Department of Mechanical Engineering, Institute of Engineering, Tribhuvan University \\ Corresponding Email: " ashokprasadaryal@gmail.com
}

\begin{abstract}
The renewable sources such as solar, wind, biomass, etc. are often used for electricity generation for their availability, no green-house gas emission and solar photovoltaic is major among them. Many On-Grid PV systems are being installed around the globe nowadays to reduce electricity dependency on a single source and thus enhance availability of energy sources. Kathmandu, Nepal receives sufficient sunshine with insolation around 4.5 to $5 \mathrm{kWh} / \mathrm{m}^{2} / \mathrm{day}$, which justifies essence of grid-connected solar PV installations. A $115.2 \mathrm{kWp}$ solar plant has been installed at Tribhuvan University Teaching Hospital (TUTH), Maharajgunj, Kathmandu to fulfill its own load demands and reduce the electricity bill of the building. The generated energy is not fed to the grid currently. The detailed On-Grid solar PV system is modeled, and performance parameters such as Performance Ratio, Specific Yield and Capacity Utilization Factor as defined by International Electro technical Commission are estimated using simulation techniques from PVSYST. The actual generation of the existing system within one year of installation is measured to be $35 \mathrm{MWh}$ but simulation tool suggests that total 199 MWh can be generated using similar capacity panel, with system being totally on-grid type. Using PVSYST, the performance parameters are found to be performance ratio $83.5 \%$ and Specific Yield $1728 \mathrm{kWh} / \mathrm{kWp}$ respectively. Thus, this paper intends to calculate performance parameters of existing system as well as performance of identical sized, totally on-grid system, simulated using PVSYST.
\end{abstract}

\section{INTRODUCTION}

$\mathrm{E}$ LECTRICITY has been a basic source for energy generation and most of appliances, nowadays run on electric power. The solar PV is widely renowned for its simplicity in installation as compared to other sources such as geothermal and tidal energy. Most of the higher capacity (in $\mathrm{kW}$ ) PV systems are directly grid-connected, with no battery bank. Diversification of energy sources, other than hydroelectric plants is one of the major techniques to overcome the current energy deficit scenario [1].

The Performance evaluation of $10 \mathrm{MW}$ grid connected solar photovoltaic (PV)system in India had been done by B. Shiva Kumar, K. Sudhakar and found out that the performance ratio was $86.12 \%$, Capacity Utilization factor $17.68 \%$, receiving annual irradiation of average $4.97 \mathrm{kWh} / \mathrm{m}^{2} /$ day [3]. Sunfarmer Nepal has signed a long-term agreement with Bayalpata Hospital, Achham to install $100 \mathrm{kWp}$ solar PV and already, $42 \mathrm{kWp}$ of solar has been installed to power critical, life-saving equipment. $1 \mathrm{kWp}$ grid connected PV system has been installed at Centre for Energy Studies/Institute of Engineering to study the performance analysis of it and its effect on utility system [2].

According studies, PV power plants' performance depends on numerous parameters that amount to many loss mechanisms [3]. Notably, the specific losses associated with a given PV plant can be categorized into two groups, namely, system losses and capture losses. Capture losses are caused by factors such as attenuation of the incoming light, soiling of PV module surface; ambient temperature, electrical mismatching, and system losses are identified as wiring losses, transformer losses, inverter losses, etc. [4].

A feasibility study of grid-connected solar system was done at Teaching Hospital which showed almost $950 \mathrm{kWp}$ can be installed at rooftop of the hospital. Already, $115.2 \mathrm{kWp}$ of the system has been installed which has been providing power backup to the Intensive Care Units and Operation Theatre loads such as X-Ray, Ventilator, MRI Machine, etc. Other similar systems are yet to be installed at the hospital. This article presents the total amount of energy that could be generated, if it was an on-grid connection system using PVSYST.

\section{SYSTEM DESCRIPTION}

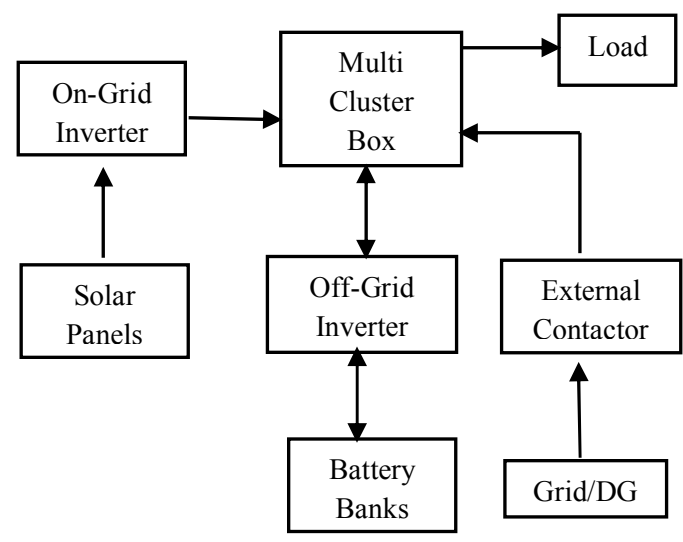

Fig.1. Existing System Block Diagram

The existing system consists of 384 identical Risen panels, each rated $300 \mathrm{Wp}$ at Standard Temperature Conditions. The DC output is inverted at first by On-Grid inverters, then sent to multicluster box, or a common Copper bus-bar from where it is further sent to off-grid inverters and then to charge the battery bank, or to supply the loads. The external supply from Grid or Diesel Generator is controlled by an external contactor (300 A), which also prevents reverse power flow from solar PV to grid through the help of OffGrid inverters. The On-Grid inverters are capable of producing 3-phase AC output whereas, the Off-Grid inverters control the battery charging and power supply to the load. The load is supplied with power according to priority set by the Off-Grid inverter, example, first the Solar, then battery and Grid or DG at the least priority. The power flow to battery is bidirectional, i.e. the off-grid inverter charges the battery when solar generation is surplus to the 
load and discharges the battery when solar generation is insufficient to the load power. The off grid inverter is also capable of supplying reactive power as required to the load. The existing connected loads are X-Ray, Ventilator, Air Conditioner, Electric Heater, Lights, Monitor, and Desktop/Laptops, overall measured to be around $26 \mathrm{~kW}$ (average). Since the site is hospital, the average load remains almost constant throughout the annum. The performance shows that $35 \mathrm{MWh}$ of energy has been generated from the existing system during the first year of installation [5]

\section{NEW PROPOSED SYSTEM}

A fully On-Grid System is shown in figure 1 which consist of no off-grid inverter and battery bank. Also, the dual energy transfer between solar PV system and Grid is recorded by the Energy meter. Thus, the energy being sent to the grid and consumed from the grid can be determined. Such system decrease the system cost due to reduction in battery components, which constitute a large share of total project costs and less life time (5-10 years) as well as optimize the energy generation, as energy can flow to the grid when generation is surplus to the battery and load requirements. A similar model is simulated in PVSYST:

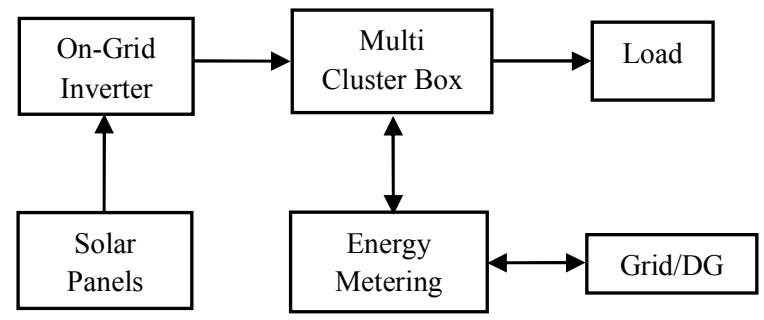

Fig.2. On-Grid System Block Diagram

\section{Definition of PERformance Parameters}

The proposed model has been simulated in PVSYST, and parameters describing energy quantities for the PV system and its components have been established by the International Energy Agency (IEA) Photovoltaic Power Systems Program and are described in the IEC standard 61724.[6]

The location was extracted through geographical coordinates $\left(27.73^{0} \mathrm{E}, 85.33^{\circ} \mathrm{N}\right)$, at TUTH, Maharajgunj at a height of $1327 \mathrm{~m}$ above the sea level. The tilt angle was adjusted $30^{\circ}$ and azimuth angle $0^{\circ}$ and shading effect being neglected. The solar irradiation data was taken from Meteonorm 7.1 (1981-2010).

The major performance parameters are specific yield and performance ratio. The specific yield is calculated as:

Specific Yield $=\frac{\text { Actual Energy From Plant }(\mathrm{kWh})}{\text { Total Nameplate DC Capacity }\left(\mathrm{kW}_{\mathrm{P}}\right)}$

It is often denoted by $Y_{F}$. The performance ratio is the ratio of actual to theoretically possible energy output. It is a measure of the quality of a PV plant that is independent of location and it therefore often described as a quality factor.
The performance ratio (PR) is stated as percent and describes the relationship between the actual and theoretical energy outputs of the PV plant.

P.R. $=\frac{\text { Actual Energy from Plant }(\mathrm{kWh})}{\text { Calculated Nominal Plant Output }(\mathrm{kWh})}$

A well-efficient solar plant should have Performance ratio in the range of $80 \%$ or above.

\section{SIMULATION USING PVSYST}

The array matrix is defined in PVSYST, the required Panel and Inverter from PVSYST database is chosen and thus, a system of $115.2 \mathrm{kWp}$ is simulated. The details of solar panel used is:

TABLE 1

\begin{tabular}{cc}
\multicolumn{2}{c}{ Parameters of Solar Panel } \\
\hline \hline $\mathrm{P}_{\mathrm{MAX}}$ & $300 \mathrm{Wp}$ \\
$\mathrm{V}_{\text {MPP }}$ & $35.9 \mathrm{~V}$ \\
$\mathrm{I}_{\mathrm{MPP}}$ & $8.36 \mathrm{~A}$ \\
$\mathrm{~V}_{\mathrm{OC}}$ & $44.9 \mathrm{~V}$ \\
$\mathrm{I}_{\mathrm{SC}}$ & $8.85 \mathrm{~A}$ \\
Efficiency(Panel) & $15.5 \%$ \\
Power Tolerance & $3 \%$ \\
Dimensions (mm) & $1956 \times 992 \times 40$ \\
\hline \hline
\end{tabular}

Similar 384 numbers of Risen SYP 300S panels were used. The inverter used was 4 number of on-grid inverter, Sunny Tripower 25000 TL-30 of $25 \mathrm{kVA}$ capacity each and fifth inverter, Sunny Tripower $15000 \mathrm{TL}-10$ of $15 \mathrm{kVA}$. The total inverter size was $115 \mathrm{kVA}$. These are highly efficient ongrid MPPT inverters with inbuilt charge controllers. The array was designed in PVSYST as:

TABLE 2

Simulation array in PVSYST

\begin{tabular}{ccc}
\hline \hline Array & Total Panels $\left(\mathbf{N}_{\mathbf{S}} \times \mathbf{N}_{\mathbf{P}}\right)$ & Capacity $(\mathbf{k W p})$ \\
\hline 1 & $10 \times 8=80$ & 24 \\
2 & $10 \times 8=80$ & 24 \\
3 & $10 \times 8=88$ & 26.4 \\
4 & $11 \times 8=88$ & 26.4 \\
5 & $20 \times 2=40$ & 12 \\
6 & $9 \times 1=8$ & 2.4 \\
Total & 384 no.s & $115.2 \mathrm{kWp}$ \\
\hline \hline
\end{tabular}

The simulation showed following data:

TABLE 3

Detailed parameters obtained from PVSYST

\begin{tabular}{ccccccc}
\hline \hline & Irr. & Temp & $\mathbf{E}_{\text {ARRAY }}$ & $\mathbf{E}_{\text {GRID }}$ & $\mathbf{Y}_{\mathbf{F}}$ & P.R. \\
\hline Jan & 136.3 & 8.7 & 20.63 & 19.96 & 173.26 & 86.3 \\
Feb & 132 & 13.14 & 17.43 & 16.86 & 146.35 & 85.0 \\
Mar & 177.9 & 18.64 & 20.13 & 19.46 & 168.92 & 82.3 \\
Apr & 181.2 & 23.50 & 17.54 & 16.97 & 147.31 & 81.0 \\
May & 189.7 & 24.86 & 16.99 & 16.44 & 142.71 & 81.6
\end{tabular}




\begin{tabular}{ccccccc}
\hline June & 166.4 & 24.05 & 14.47 & 13.99 & 121.44 & 82.5 \\
July & 154.8 & 23.20 & 13.79 & 13.33 & 115.71 & 83.3 \\
Aug & 151.7 & 23.08 & 14.45 & 13.97 & 121.27 & 83.1 \\
Sept & 136.4 & 22.20 & 14.24 & 13.77 & 119.53 & 82.6 \\
Oct & 140 & 20.14 & 16.65 & 16.10 & 139.76 & 82.8 \\
Nov & 129.8 & 15.36 & 18.60 & 18.00 & 156.25 & 84.4 \\
Dec & 130 & 10.86 & 20.91 & 20.23 & 175.61 & 85.7 \\
Year & $\mathbf{1 8 2 6}$ & $\mathbf{1 9 . 0 0}$ & $\mathbf{2 0 5 . 8 3}$ & $\mathbf{1 9 9 . 1}$ & $\mathbf{1 7 2 8 . 1}$ & $\mathbf{8 3 . 5}$ \\
\hline \hline
\end{tabular}

Legends:

Irr Global Horizontal Irradiance in $\mathrm{kWh} / \mathrm{m}^{2}$

Temp Temperature in ${ }^{0} \mathrm{C}$

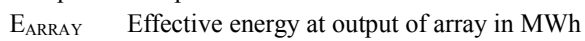

$\mathrm{E}_{\mathrm{GRID}} \quad$ Effective energy injected into grid in MWh

$\mathrm{Y}_{\mathrm{F}} \quad$ Specific Yield in $\mathrm{kWh} / \mathrm{kWp}$

PR Performance Ratio in \%

Thus, simulation of the system in PVSYST showed that 199.1 MWh energy could be injected to the grid annually, and the total irradiation falling on horizontal surface is $1826.2 \mathrm{kWh} / \mathrm{m}^{2}$ annually. The annual performance ratio and specific yield are $83.5 \%$ and $1728.1 \mathrm{kWh} / \mathrm{kWp}$, respectively. The energy losses during grid injection are 6.82 MWh annually.

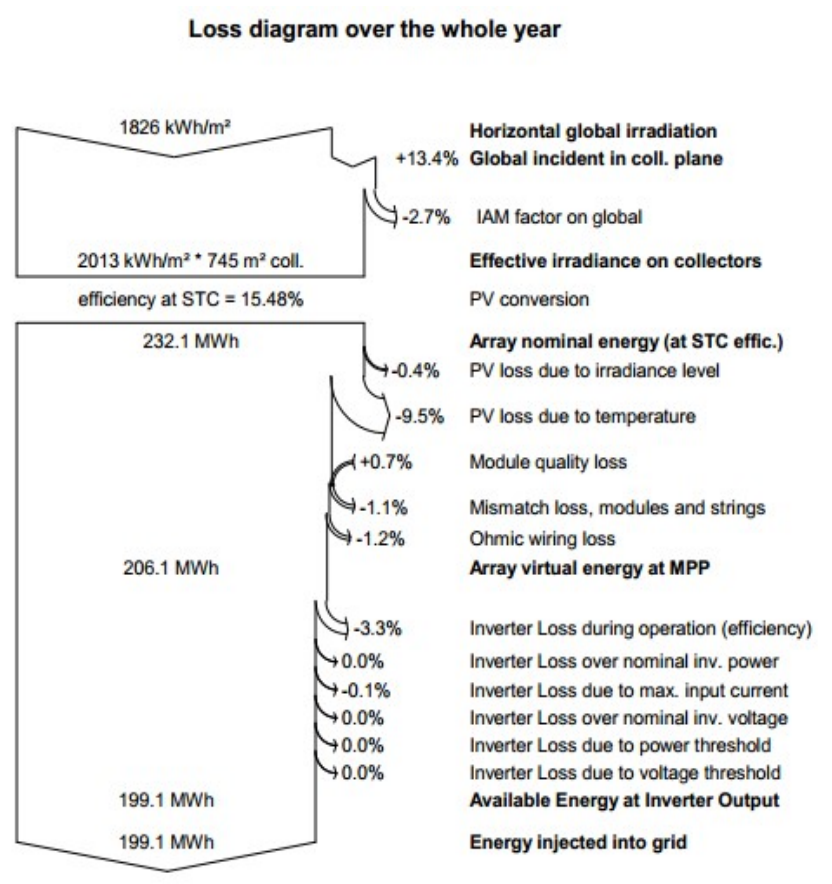

Fig.2. Sankey Diagram over the year generated by PVSYST

\section{RESULTS AND DISCUSSION}

Thus, the monthly generation was obtained as:

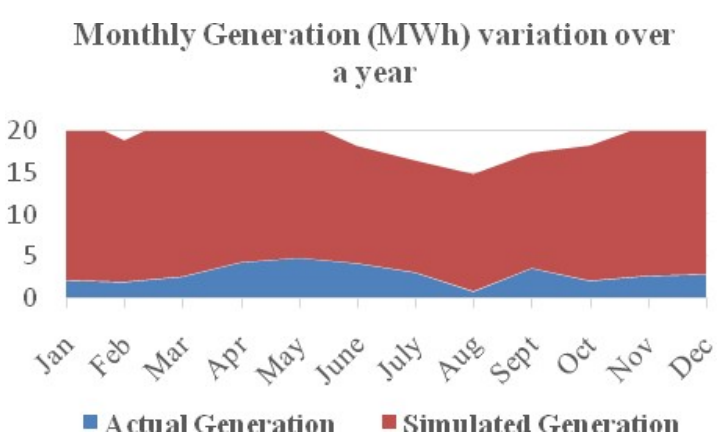

Fig.3. Monthly Energy Generation variation with irradiances

This graph shows the monthly variation of actual Energy generated as well as simulated value of energy that can be sent to the grid by array. The generation is maximum during Dec-Jan and least during June-July. The total generation throughout the year is $206 \mathrm{MWh}$ by a $115.2 \mathrm{kWp}$ solar PV installed at Kathmandu, Nepal. The actual generation was only $35 \mathrm{MW}$.

\section{Actual and Simulated P.R. (\%) Variation}

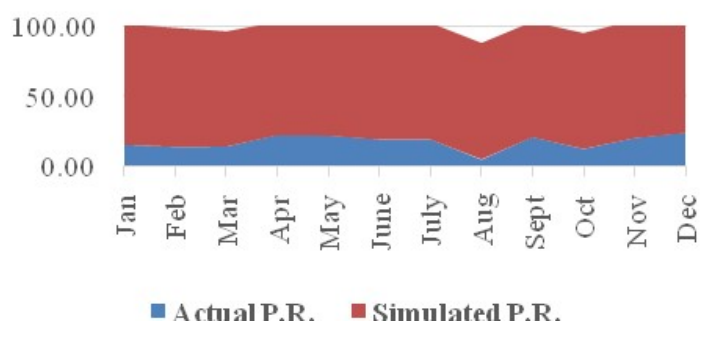

Fig.4. Performance Ratio variation over the year

The performance ratio variation shows the maximum value for January (86.3\%) and least value for April (81\%) with an annual average value of $83.5 \%$. The actual performance ratio obtained, however is only $17 \%$ annually.

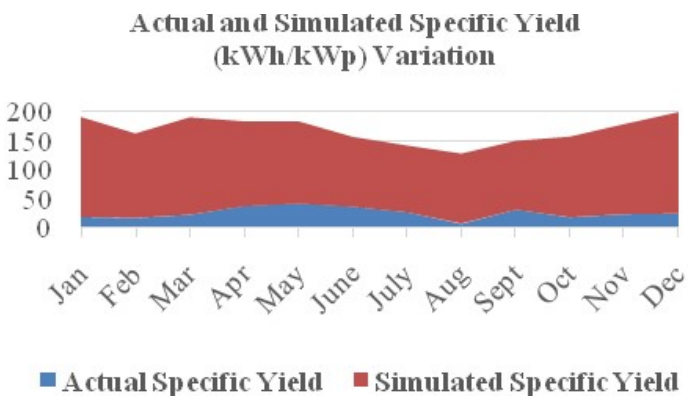

Fig.5. Specific Yield variation over a year

The actual specific yield is only $304.28 \mathrm{kWh} / \mathrm{kWp}$ annually, whereas the simulated system shows specific yield upto $1728 \mathrm{kWh} / \mathrm{kWp}$ can be obtained. 


\section{CONCLUSION}

The simulation results from PVSYST shows that a 115.2 $\mathrm{kWp}$ On-Grid system is capable of injecting $199 \mathrm{MWh}$ energy annually to the grid, with annual average performance ratio of $83.5 \%$ and annual specific yield of $1728 \mathrm{kWh} / \mathrm{kWp}$. The shading loss is neglected and grid availability is considered $100 \%$. Similar studies by Sharma et al. at India shows annual performance ratio of 78\%.[7] The actual generation of the existing plant with battery bank, off-grid and on-grid inverters is only $35 \mathrm{MWh}$ for the first year of its installation. This actual generation is recorded on-site using a data logger. Thus, an on-grid system can be recommended as compared to similar existing PV system at TUTH during next phase of solar PV installation for better performance and optimized energy generation. The current system is working, but with certain modifications, it can be made fully on-grid to optimize the generation, with other input parameters remaining the same and reduced project costs.

\section{REFERENCES}

[1] Chianese, D., Pittet, D., Shrestha, J. N., Sharma, D., Zahnd, A., Sanjel, N.,. \& Uphadyaya, M., "Feasibility study on Grid connected PV system in Nepal," 2009.

[2] Nawraj Bhattarai, "Study on Grid Connected Systems in Nepal," Master's Thesis , 2004.

[3] Ugwu, H. U., Nwankwojike, B. N., Ogbonnaya, E. A., \& Ekoi, E. J, "Energy and Economic losses due to constant power outages in Nigeria," Nigerian Journal of Technology, pp. 181-188, 2012.

[4] A. P. Dobos, PVWatts version 5 manual. National Renewable Energy Laboratory., 2014.

[5] Aryal, A., \& Bhattarai, Nawraj, "Performance Analysis of Solar PV System of Teaching Hospital, Kathmandu, Nepal ," in Proceedings of IOE Graduate Conference., 2017.

[6] British Standard, "Photovoltaic system performance onitoring — guidelines for measurement, data exchange and analysis," pp. BS EN, 61724, 1998.

[7] Sharma, V., \& Chandel, S. S. , "Performance analysis of a $190 \mathrm{kWp}$ grid interactive solar photovoltaic power plant in India," Energy 55, pp. 476-485., 2015.
Sandeep Giri, "Nepal gets 2 to 3 times solar energy than

[8] world solar leader German," 2010.

[9] Kumar, B. S., \& Sudhakar, K. , "Performance evaluation of $10 \mathrm{MW}$ grid connected solar photovoltaic power plant in India," Energy Reports, 1, pp. , 184-192. doi:10.1016/j.egyr.2015.10.001, 2015.

[10] Karki, P., Adhikary, B., \& Sherpa, K., "Comparative study of grid-tied photovoltaic (PV) system in Kathmandu and Berlin using PVSYST," , 2012, pp. doi:10.1109/icset.2012.6357397.

\section{ACKNOWLEDGEMENT}

The authors would like to express their sincere thank to Er. Pradip Humagain, Ghampower Pvt. Ltd. for providing required technical assistance.

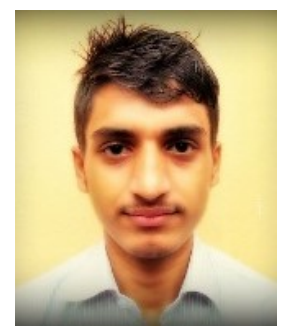

\section{BIOGRAPHIES}

Ashok Aryal is a graduate student of Master of Science in Renewable Energy Engineering from Pulchowk Campus, Institute of Engineering (IOE), Tribhuvan University (TU) and completed his Bachelor's degree in Electrical Engineering from Pulchowk Campus, IOE, TU. He is currently working as an Electrical Engineer at Industrial District Management Limited (IDML), Balaju. His research interests are various areas of renewable energy such as Wind Energy, Photovoltaics, etc.

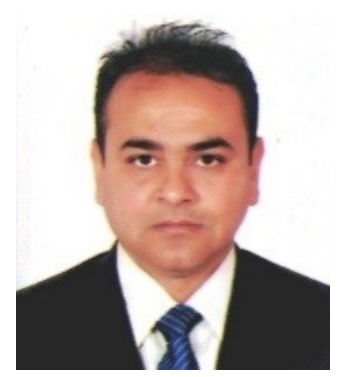

Nawraj Bhattarai is currently working as the Head of Department (HoD) at the Department of Mechanical Engineering, Pulchowk Campus, Institute of Engineering, Tribhuvan University. $\mathrm{He}$ received his Ph.D. degree in Energy Planning from Vienna University of Technology, Austria. He completed his M.Sc. in Renewable Energy Engineering and Bachelors in Mechanical Engineering from Pulchowk Campus, IOE, TU. He has already been involved as an expert in many national and foreign renewable energy related projects. He has published several articles in different journals. His research interests are micro-hydro technology, pollution and climate change, environmental engineering, etc. 